\title{
Axial Force Analysis and Roll Contour Configuration of Four-High CVC Mill
}

\author{
Guang-ming Liu $\mathbb{D}^{1,},{ }^{1,2}$ Yu-gui Li $\mathbb{D}^{1,2}$ Qing-xue Huang, ${ }^{1}$ and Xia Yang ${ }^{1}$ \\ ${ }^{1}$ Heavy Machinery Engineering Research Center of the Ministry of Education, Taiyuan University of Science and Technology, \\ Taiyuan, Shanxi 030024, China \\ ${ }^{2}$ College of Materials Science and Engineering, Taiyuan University of Science and Technology, Taiyuan, Shanxi 030024, China
}

Correspondence should be addressed to Yu-gui Li; liyugui2008@163.com

Received 24 July 2017; Accepted 14 September 2017; Published 4 January 2018

Academic Editor: Marco Pizzarelli

Copyright (c) 2018 Guang-ming Liu et al. This is an open access article distributed under the Creative Commons Attribution License, which permits unrestricted use, distribution, and reproduction in any medium, provided the original work is properly cited.

\begin{abstract}
In order to analyze the influence of technical parameters on work roll axial force of four-high continuous variable crown (CVC) mill, the deformation analyzing model with top roll system and strip was established based on influence function method. Then a CVC work roll curve designing scheme was proposed and it was carried out on some cold rolling mill considering the requirement of comprehensive work roll axial force minimization. The status of comprehensive work roll axial force is improved considering the rolling schedule that is beneficial to the roller bearing. Corresponding to the newly designed work roll contour, the backup roll end chamfer was designed considering comprehensive performance of interroll stress concentration, comprehensive work roll axial force, and strip shape control ability. The distribution of roll wear with newly designed backup roll contour is more even according to the field application data. The newly established roll configuration scheme is beneficial to four-high CVC mill.
\end{abstract}

\section{Introduction}

Rolling process simulation is a feasible method to analyze the rolling technology and characteristic of equipment and control system. The popular simulating methods for strip rolling process analysis include finite element method, boundary element method, and influence function method. Among them, influence function method is always chosen for fewer assumptions, faster calculation speed, and better calculation accuracy which satisfy the requirement of project well. It is first proposed by Edwards and Spooner [1] based on the work of Shohet and Townsend [2], improved by Nakajima [3], Tozawa and Ishikawa [4], and Wang [5] subsequently, and now the influence function method has become relatively sound.

Many rolling process analyses were carried out using influence function method. Jiang et al. [6] obtained the rolling force, intermediate force, roll edge kiss force, and strip shape in cold rolling of ultra-thin strip with roll edge kiss. Gong et al. [7] analyzed the regularity of roll elastic deformation under the condition of different stiffness between the driving side and operating side. Liang [8] established the elastic deformation model for the roll stack of six-high cold rolling mill and the preset model of intermediate and work roll bending force. Wang et al. [9] proposed a high-efficiency calculation method of roll stack elastic deformation for four-high mill and obtained strip thickness distribution, rolling pressure, and pressure between rolls. Chen et al. [10] established the models of rolls system elastic deformation and roll flattening deformation considering work roll contact.

Load distribution optimization is a feasible way for strip shape control in the traditional rolling mills, while its effect is limited [11]. The CVC system is developed as a more effect control method and is employed on many cold rolling and hot rolling mills [12]. The work rolls of the fourhigh CVC mill both have an "S" shape and are arranged antisymmetrically. Through the axial shifting of two work rolls towards each other, a continuously adjustable rolling gap contour could be obtained. Lu et al. [13] presented a design method of a third-order CVC roll contour considering the axial force minimization as the design criteria of monomial coefficient. Wei et al. [14] gave a CVC work roll designing method considering the minimization of work roll diameter difference along the barrel. Liu et al. [15] presented a CVC 


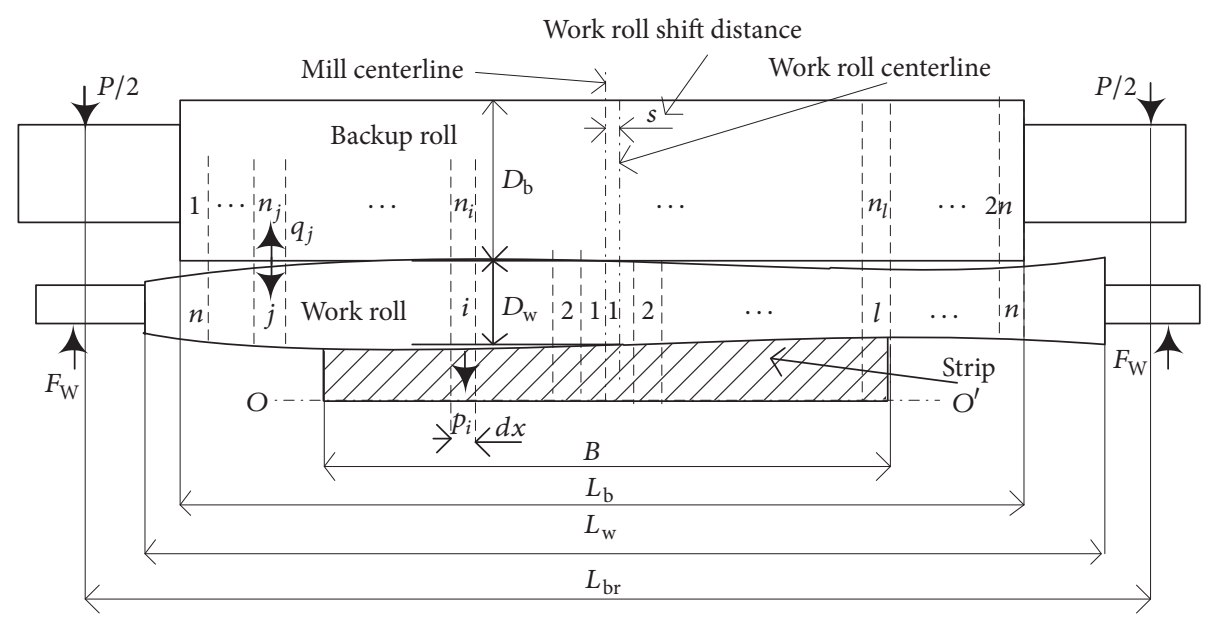

FIgURE 1: Roll system of CVC mill with strip.

work roll contour design method considering the effective crown control range corresponding to the maximum strip width. The quadratic and cubic coefficients of the third-order curve are determined by the strip crown control range, while the monomial coefficient is acquired through minimization of work roll axial force. However, the work roll axial force is calculated only considering the original work roll contour and axial component of rolling force whose distribution is regarded as uniform.

There is a force concentration at the backup roll end for the CVC roll system which usually causes series abrasion or surface spalling [16-20]. Cao et al. [21] presented a parameter to appraise the roll contour self-maintenance and analyzed the backup roll wear of hot wide strip mill. Cao et al. [22] also used this method to evaluate the self-maintenance of an asymmetry self-compensating work roll for schedule-free rolling in a $1700 \mathrm{~mm}$ hot strip mill. Xu et al. [23] applied this method on CVC work roll wear of hot strip finishing mill. Hao et al. [24] presented a CVC-VCR (variable contact backup roll) compounded backup roll contour in order to avoid the serious and nonuniform wear and edge spalling. Sun et al. [25] analyzed the distribution of contact pressure between rolls of three kinds of different chamfer shapes at the end of backup rolls and compared it with that without chamfer. Liu et al. [26] analyzed the influence of strip width, shift position, bending force, backup roll crown, and parameter of circle and parabolic chamfer on interroll contact pressure distribution. Guo et al. [27] analyzed the influence of different large-arc compound chamfer parameters on lateral stiffness, adjustment efficiency of bending force, and roll uneven wear. Wang et al. [28] gave a pressure-equalizing backup roll contour with combination of variable crown backup roll and CVC backup roll contours in order to improve the contact condition between work and backup roll. Kong et al. [20] developed a smart contact backup roll for homogenizing contact pressure between rolls and minimizing the harmful contact zone in different strip width in order to solve the serious backup roll spalling. Most influencing factors on interroll force concentration and strip shape control ability were considered separately in the above analyses. Although a chamfer with relatively better performance is provided, a systematic designing scheme considering the comprehensive performance has not been proposed.

In this paper, the deformation model of top roll system and strip with influence function method was established. A new comprehensive work roll axial force calculation method was established considering the comprehensive work roll contour with backup roll and strip. The influence factors on comprehensive work roll axial force were analyzed. Then a new work roll contour designing method was proposed considering the comprehensive work roll axial force minimization, work roll diameter difference minimization, and rolling schedule. Corresponding to the newly designed CVC work roll, the backup roll end chamfer was optimized by minimization of objective function value composed of interroll force concentration, comprehensive work roll axial force, and shape control ability. Then the roll contour configuration scheme for four-high CVC mill is established systematically.

\section{Roll Deformation of 4-High CVC Mill}

Influence function method is established according to deformation energy principle considering the backup and work rolls as double-layer elastic foundation beam. In this research, the rolls are considered as double cantilever model and the fulcrum of the beams is in the mill centerline. On each side of the fulcrum, there is a cantilever beam for the backup roll and work roll, respectively. The deformation model with top roll system and strip of CVC mill and the representative parameters are shown in Figure 1. In the rolling process with work roll shift distance $s$, the strip slice elements on operation and driving side are both $l$, and the slab elements of contact area between work roll and backup roll of both sides are $n$. $d x$ is the width of slice element. $P$ is the total rolling force. $p_{i}$ is the rolling force at element $i . q_{j}$ is the contact force between work roll and backup roll at element $j . F_{\mathrm{W}}$ is the work roll bending force. $L_{\mathrm{br}}$ is the distance between two work roll bending cylinders or two mill screwdown cylinders. $L_{\mathrm{b}}$ is the width of backup roll barrel. $L_{\mathrm{w}}$ is the width of work roll barrel. 
$B$ is the strip width. $D_{\mathrm{b}}$ is the backup roll diameter. $D_{\mathrm{w}}$ is the nominal diameter of work roll.

2.1. Split of Roll and Strip. For the top and bottom work roll is arranged antisymmetrically, and the distribution of unit rolling force, strip deformation, and exit thickness will be symmetric with mill centerline. While the distribution of interroll force is in an "S" form due to the special CVC work roll contour, the elastic deformation of top and bottom rolls will be antisymmetric, respectively [26]. The force between work roll and backup roll or strip is discretized using the same method as rolls; the distributed force of each element is represented by the concentrated load of the element. As shown in Figure 1, there are two element numbering rules, the first is from the left to the right of backup roll, and the second is from rolling centerline to both left and right sides. The rolling force, interroll force, work roll deflection, backup roll deflection, interroll flattening, and work roll-strip flattening are all expressed by vectors as in [5]. There are seven equations for elastic deformation calculation of four-high rolling mill including four deformation equations, one force balancing equation, and two deformation compatibility equations.

2.2. Elastic Deformation Calculation. The forces cause the work roll deflection including rolling force, interroll force, and work roll bending force, so work roll deflection at element $i$ could be expressed as $[5,6]$

$$
y_{\mathrm{W}}(i)=\sum_{j=1}^{n} g_{\mathrm{W}}(i, j)(q(j)-p(j))-g_{\mathrm{FW}}(i) F_{\mathrm{W}},
$$

where $g_{\mathrm{W}}(i, j)$ is the work roll deflection influence function due to the combined bending and shear forces generated by rolling and interroll force at element $j ; g_{\mathrm{FW}}(i)$ is the work roll bending influence function due to the work roll bending force.

The backup roll deflection is caused only by the interroll force, so backup roll deflection at element $i$ could be expressed as $[5,6]$

$$
y_{\mathrm{B}}(i)=\sum_{j=1}^{n} g_{\mathrm{B}}(i, j) q(j),
$$

where $g_{\mathrm{B}}(i, j)$ is the backup roll deflection influence function due to the combined bending and shear forces generated by interroll force at element $j$.

The force causing flattening between work roll and strip is the rolling force, and the force causing the flattening between work roll and backup roll is the interroll force, so flattening at element $i$ could be expressed as $[5,6]$

$$
\begin{aligned}
& y_{\mathrm{WS}}(i)=\sum_{j=n_{\mathrm{L}}}^{n_{\mathrm{R}}} g_{\mathrm{WS}}(i, j) p(j) \\
& y_{\mathrm{WB}}(i)=\sum_{j=1}^{2 n} g_{\mathrm{WB}}(i, j) q(j),
\end{aligned}
$$

where $g_{\mathrm{Ws}}(i, j)$ is the flattening influence function of work roll and strip due to the rolling force at element $j ; n_{\mathrm{L}}$ and
$n_{\mathrm{R}}$ are the element numbers at left and right edge of strip according to the second numbering rule; $g_{\mathrm{WB}}(i, j)$ is the flattening influence function of work roll and backup roll due to the interroll force at element $j$.

2.3. Force Balance Relation. The force applied to the work roll in the rolling process includes deformation force from strip, the work roll bending force from bending cylinder, and the interroll force between work roll and backup roll, and these forces should be balanced. Then the relationship can be expressed as $[5,6]$

$$
2 \sum_{i=1}^{l} p_{i}+2 F_{\mathrm{W}}=\sum_{j=1}^{2 n} q_{j}
$$

2.4. Deformation Compatibility Relation. The compatibility for the contact of work roll and backup roll varies by the backup roll deflection, work roll deflection, roll crown, and flattening between work roll and backup roll. It could be expressed as $[5,6]$

$$
y_{\mathrm{WB}}(i)=y_{\mathrm{WB} 0}(i)+y_{\mathrm{B}}(i)-y_{\mathrm{W}}(i)-m_{\mathrm{W}}(i)-m_{\mathrm{B}}(i),
$$

where $y_{\mathrm{WB} 0}(i)$ is the centerline flattening between work roll and backup roll; $m_{\mathrm{W}}(i)$ and $m_{\mathrm{B}}(i)$ are the combined grinded and thermal cambers of work roll and backup roll at element $i$, respectively.

The compatibility for the contact of strip and work roll varies by the work roll deflection, roll crown, and flattening between work roll and strip. Then the compatibility relation could be expressed as $[5,6]$

$$
h(i)=h_{0}(i)+y_{\mathrm{WS}}(i)-y_{\mathrm{Ws} 0}(i)+m_{\mathrm{W}}(i)-y_{\mathrm{W}}(i),
$$

where $h(i)$ is the exit thickness of element $i$ above symmetric line of top and bottom roll system; $h_{0}(i)$ is the exit thickness at the rolling centerline above symmetric line; $y_{\mathrm{Ws}}(i)$ is the centerline flattening between work roll and strip; $y_{\mathrm{wS}}(i)$ is the flattening between work roll and strip; $m_{\mathrm{W}}(i)$ is the combined grinded and thermal cambers of work roll; $y_{\mathrm{W}}(i)$ is the deflection of work roll.

\section{Axial Force Analysis}

The parameters used in the simulation are as follows: work roll nominal diameter, $450 \mathrm{~mm}$; work roll barrel, $1950 \mathrm{~mm}$; crown control range of the CVC work roll, $0 \sim 0.7 \mathrm{~mm}$; work roll shift range, $-100 \sim 100 \mathrm{~mm}$; Poisson's ratio of work roll, 0.3 ; Young's modulus of work roll, $22,000 \mathrm{~kg} / \mathrm{mm}^{2}$; distance between the center of two bending cylinders, $2850 \mathrm{~mm}$; backup roll normal diameter, $1250 \mathrm{~mm}$; backup roll barrel, $1750 \mathrm{~mm}$; backup roll crown, $0 \mathrm{~mm}$; Poisson's ratio of backup roll, 0.3 ; Young's modulus of backup roll, $22,000 \mathrm{~kg} / \mathrm{mm}^{2}$; distance between the center of two screwdown cylinders, $2850 \mathrm{~mm}$; entry thickness of strip, $2.80 \mathrm{~mm}$; exit thickness of strip, $2.12 \mathrm{~mm}$; strip width, $1270 \mathrm{~mm}$; back tension, $35 \mathrm{kN}$; forward tension, $145.75 \mathrm{kN}$; rolling speed, $11.75 \mathrm{~m} / \mathrm{s}$; and work roll bending force, $-350 \sim 450 \mathrm{kN}$. 


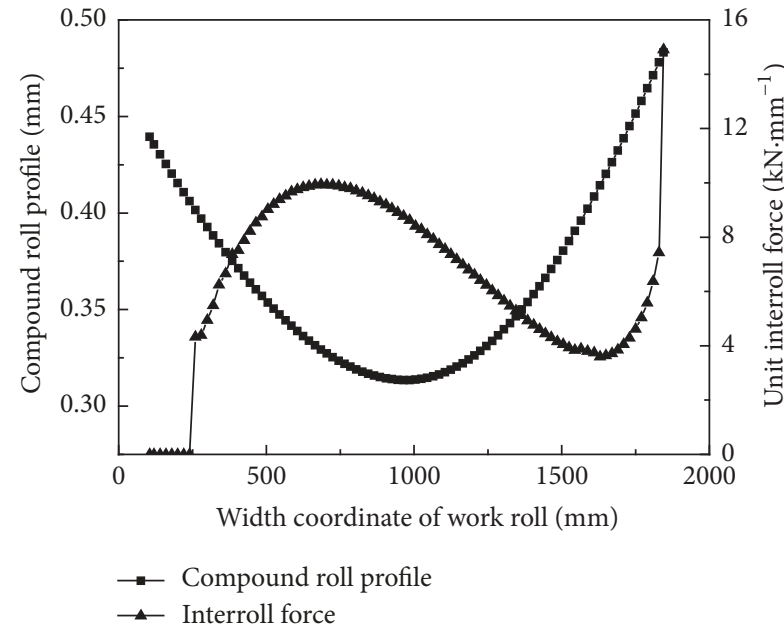

(a)

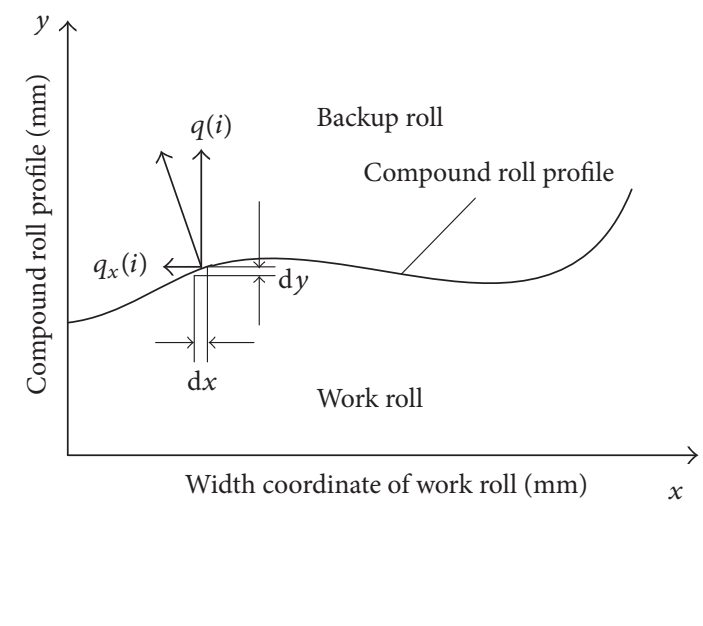

(b)

FIGURE 2: Interroll force and compound roll contour between rolls. (a) Compound roll contour and interroll force; (b) interroll force resolution.

Deformation resistance for SPCC product is expressed as

$$
\sigma_{s}=(a+b \cdot \varepsilon)\left(1-c \cdot e^{-d \cdot \varepsilon}\right),
$$

where $\sigma_{s}$ is deformation resistance, MPa: $a=592.33, b=$ 131.99 , and $c=0.61$, and $d=6.46$, and $\varepsilon$ is the true strain.

Friction coefficient of field application for SPCC product is expressed as

$$
f=a^{\prime}+b^{\prime} h+c^{\prime} \varepsilon
$$

where $a^{\prime}=0.0285, b^{\prime}=-0.0869, c^{\prime}=0.4433$, and $h$ is the exit thickness of strip.

The axial force is harmful to the roller bearing. So the axial force minimization is used in the monomial coefficient designing of CVC work roll. Usually the rolling force distribution is considered uniform and the original work roll contour parameters are used [12]. While the actual distributions of rolling force and interroll force are not uniform, then there will be axial components of them applied on work roll. Furthermore, the roll contour with elastic deformation is a compound curve which consists of grinded roll curve, roll deflection, and roll flattening. In the following analysis, the compound roll contour and actual force distribution are considered in order to get a more accurate axial force.

3.1. Comprehensive Work Roll Contour with Backup Roll. The flattening between work roll and backup roll can be divided into two parts, one part for work roll and the other for backup roll. Then the compatibility equation of work roll and backup roll can be rewritten as follows:

$$
\begin{aligned}
y_{\mathrm{WB} \_\mathrm{W}}(i)+y_{\mathrm{WB} \_\mathrm{B}}(i)= & y_{\mathrm{WB} 0}(i)+y_{\mathrm{B}}(i)-y_{\mathrm{W}}(i) \\
& -m_{\mathrm{W}}(i)-m_{\mathrm{B}}(i),
\end{aligned}
$$

where $y_{\mathrm{WB} \_\mathrm{W}}(i)$ is the interroll flattening part of work roll; $y_{\mathrm{WB} \_\mathrm{B}}(i) h(i)$ is the interroll flattening part of backup roll.
In order to obtain the compound work roll contour between work roll and backup roll, (9) could be transformed into

$$
\begin{aligned}
& y_{\mathrm{W}}(i)+m_{\mathrm{W}}(i)+y_{\mathrm{WB}_{\mathrm{W}}}(i) \\
& \quad=y_{\mathrm{WB} 0}(i)+y_{\mathrm{B}}(i)-m_{\mathrm{B}}(i)-y_{\mathrm{WB} \_\mathrm{B}}(i) .
\end{aligned}
$$

The left side of (10) could be used to denote the compound profile of work roll. Therefore, the compound profile of work roll for the above-mentioned normal rolling process is shown in Figure 2(a). The compound profile between backup roll and work roll is in an asymmetric "V" style, while the distribution of interroll force is in an "S" style as mentioned above. Then there will be an axial component of interroll force when it is actioned on an inclined plane. In the above calculation model, the rolls and strip are splinted into small slices. So in order to analyze the axial force between rolls, the same method can be used as shown in Figure 2(b). The relationship of interroll force and its axial component could be expressed as

$$
\frac{\mathrm{d} y}{\mathrm{~d} x}=\frac{q_{x}(i)}{q(i)},
$$

where $q_{x}(i)$ is the axial component of element $i$ d $x$ is the element width; $\mathrm{d} y$ is the profile variation; $\mathrm{d} y / \mathrm{d} x$ denotes the tangent value of the compound roll contour at the center of the element $i$.

In order to obtain the total axial force between rolls, the compound profile is regressed by a six-order polynomial as

$$
y_{1}(x)=\sum_{i=0}^{6} a_{i} x^{i}
$$

where $a_{i}$ are the multinomial coefficients.

The total axial force can be given as

$$
Q_{x}=\sum_{i=1}^{2 n} q(i) y_{1}^{\prime}\left(x_{i}\right),
$$

where $y_{1}^{\prime}(i)$ is the tangent value at the center of element $i$. 


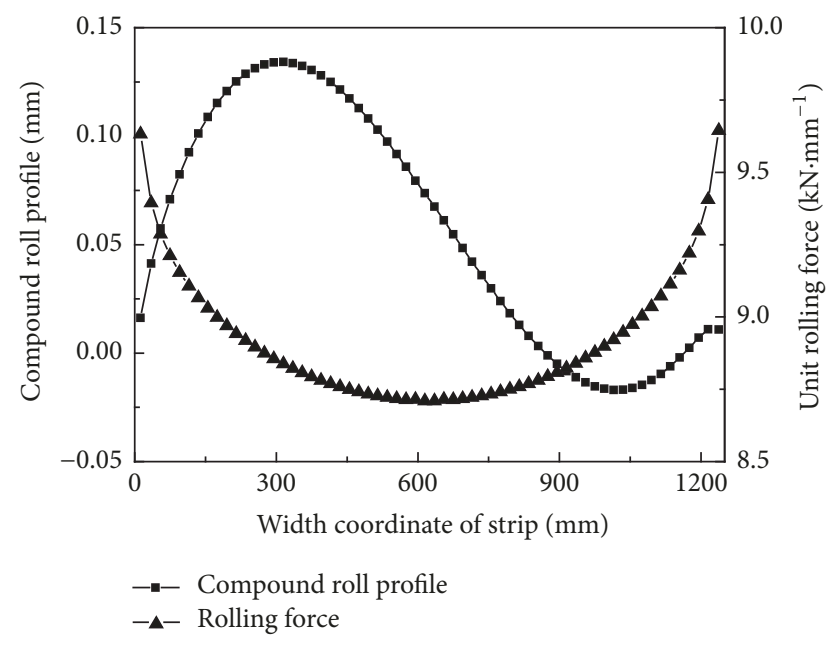

FIGURE 3: Rolling force and compound roll contour between top work roll and strip.

3.2. Compound Work Roll Contour with Strip. In order to obtain the compound work roll contour between work roll and strip, the compatibility equation of work roll and strip can be rewritten as

$$
y_{\mathrm{WS}}(i)+m_{\mathrm{W}}(i)-y_{\mathrm{W}}(i)=h(i)-h_{0}(i)+y_{\mathrm{WS} 0}(i) \text {. }
$$

The left side of (14) could be used to denote the compound profile of work roll. Therefore, the compound profile between top work roll and strip for the above-mentioned normal rolling process is shown in Figure 3. The compound profile between work roll and strip is in an " $S$ " form, while the distribution of rolling force is in a parabolic form.

By the same analysis method as interroll axial force, the relationship of rolling force and its axial component could be expressed as

$$
\frac{\mathrm{d} y}{\mathrm{~d} x}=\frac{p_{x}(i)}{p(i)},
$$

where $p_{x}(i)$ is the axial component of element $i$.

In order to obtain the total axial force between work roll and strip, the compound profile can also be regressed by a six-order polynomial as

$$
y_{2}(x)=\sum_{i=0}^{6} b_{i} x^{i}
$$

where $b_{i}$ are the multinomial coefficients.

The total axial force is given as

$$
P_{x}=\sum_{i=1}^{2 l} p(i) y_{2}^{\prime}\left(x_{i}\right) \text {, }
$$

where $y_{2}^{\prime}(i)$ is the tangent value at the center of element $i$.

3.3. Axial Force of Work Roll. For the above-mentioned normal rolling process, the total axial force between rolls is $0.162 \mathrm{kN}$ and the total axial force between work roll and strip is $0.161 \mathrm{kN}$. Then the total axial force acting on work roll is the sum of the above-mentioned two parts which is $0.323 \mathrm{kN}$. In order to analyze the influence of some technical factors on work roll axial force, the rolling processes with different technical parameters are simulated. The influences on work roll axial force of work roll shift distance, work roll bending force, strip width, and strip deformation resistance are obtained.

The influence on axial force of work roll shift positions with different bending forces is shown in Figure 4. It can be seen from Figure 4(a) that the rolling force decreases linearly, while work roll shifts from operation side to driving side. This is because that the reduction on both sides of the rolling centerline reduces; in other words, the work roll shifting makes roll gap of edge larger. Figure 4(b) shows axial force variation process with work roll shifting under different work roll bending forces. The axial force increases with work roll shifting from operation side to driving side when the work roll bending force is more than $-150 \mathrm{kN}$, where the negative sign denotes that there is a work roll negative bending force and the positive sign denotes that there is a work roll positive bending force. However, the axial force first increases and then decreases with work roll shifting from operation side to driving side when the work roll bending force is $-300 \mathrm{kN}$. And the maximum axial force is obtained when the work roll shift distance is $0 \mathrm{~mm}$. The ratio of axial force to rolling force displays the same variation regularity as the axial force as shown in Figure 4(c). It presents similar variation regularity to the axial force and the variation under bending force $-300 \mathrm{kN}$ with work roll shifting is the smallest. That is to say when the work roll bending force is $-300 \mathrm{kN}$, the axial force is relatively stable.

The variation of axial force with different bending forces under different shifting positions is shown in Figure 5. Rolling force decreases with the increase of work roll bending force as shown in Figure 5(a). This is because the above bending forces variation makes the strip reduction of the edge reduce. Figure 5(b) shows that the axial force decreases with the increase of work roll bending force when the work roll bending force is more than $-150 \mathrm{kN}$. The variation regularity is different when the work roll bending force is $-300 \mathrm{kN}$ that is the same in Figure 4. The variation regularity of ratio of axial force to rolling force is the same as the axial force as shown in Figure 5(c).

In order to analyze the influence of strip width on axial force, the simulation was carried out taking the other parameters the same as the normal rolling process. The results are shown in Figure 6. Figure 6(a) shows that the rolling force and axial force both increase with the increase of strip width. The strip width is the only variable in the simulation process and its increase will enlarge the contact area between work roll and strip. The influence of strip width on axial force cannot be clearly illustrated. So the ratio of axial force to rolling force of each width is calculated and shown in Figure 6(b). It can be seen that the ratio of axial force to rolling force first decreases and then increase with the increase of strip width. When the strip width is around $1250 \mathrm{~mm}$, the ratio of axial force to rolling force has the smallest value. When the strip width is larger than $1250 \mathrm{~mm}$, the rolling force 


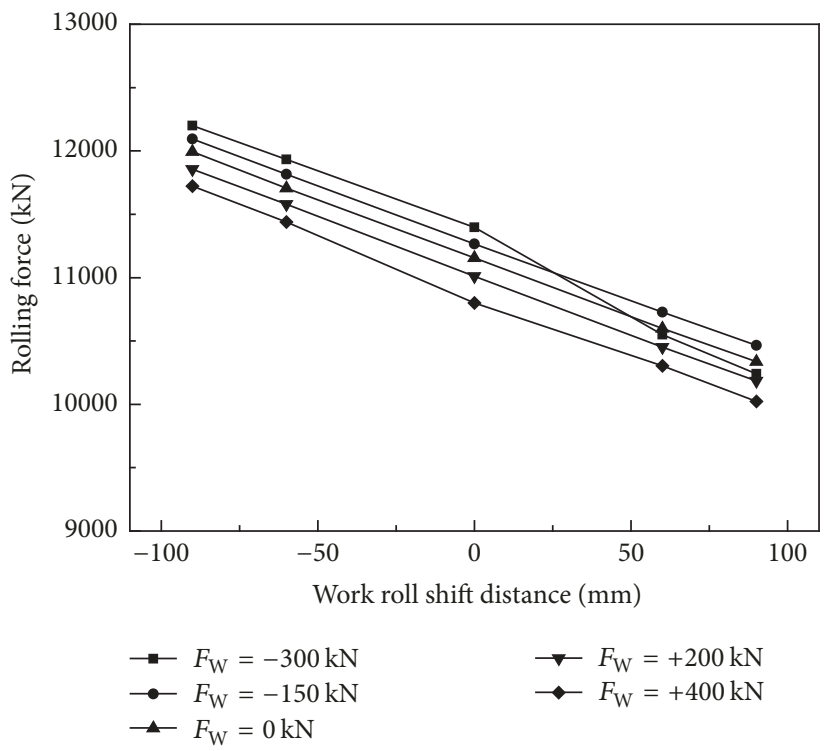

(a)

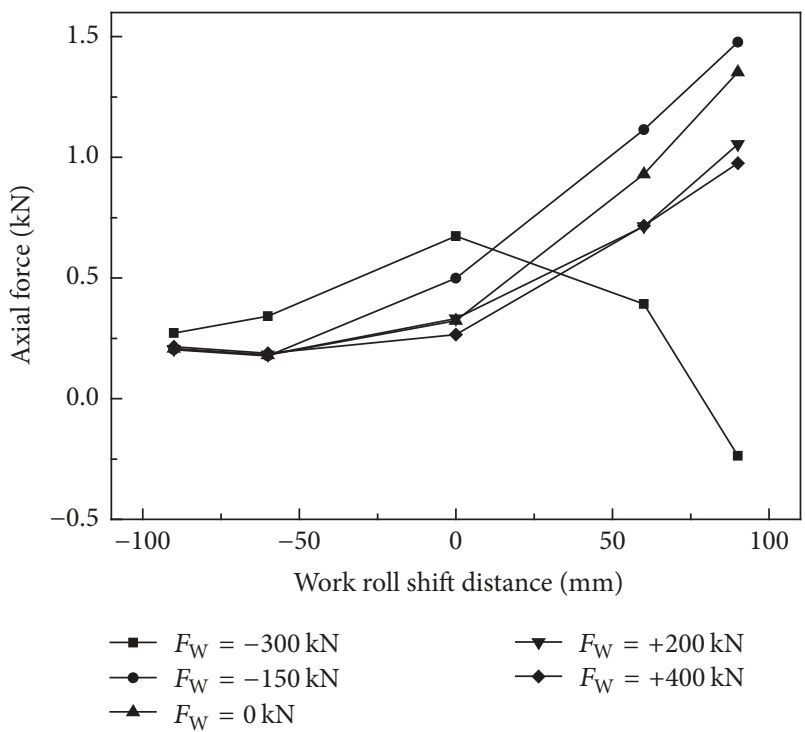

(b)

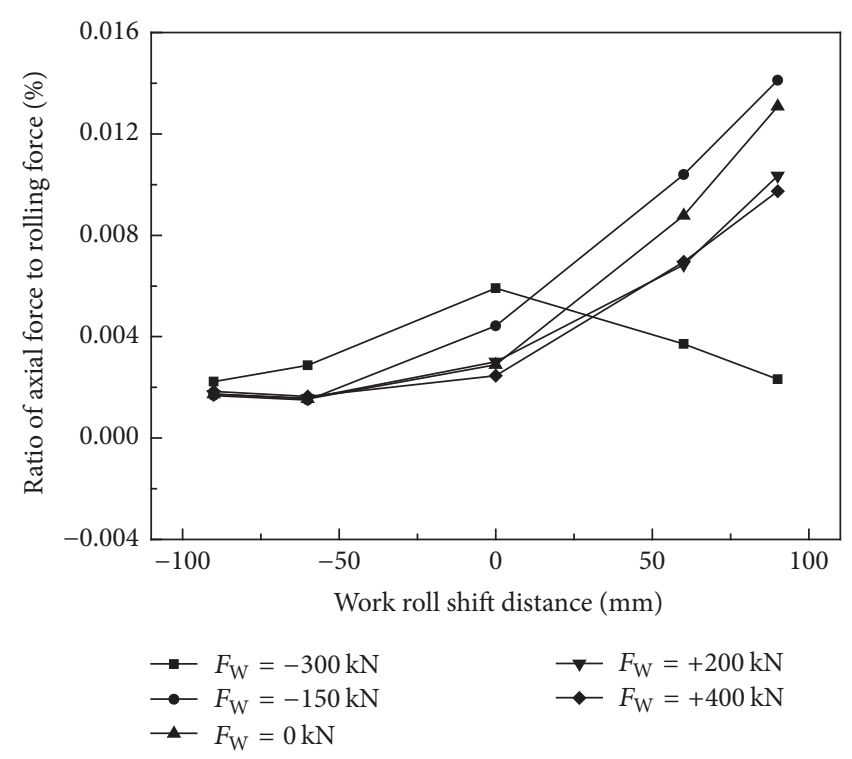

(c)

FIGURE 4: Influence on total axial force of work roll shift position. (a) Rolling force; (b) axial force; and (c) ratio of axial force to rolling force.

and ratio of axial force to rolling force both increase rapidly; that is to say axial force is more serious in the wide strip rolling process.

In order to analyze the influence of deformation resistance on axial force, the simulation was carried out taking the other parameters the same as the normal rolling process. The results are shown in Figure 7. Figure 7(a) shows that the rolling force increases with the increase of deformation resistance, while axial force first decreases and then increases with the increase of deformation resistance and has the smallest value with deformation resistance of $600 \mathrm{MPa}$. The deformation resistance is the only variable in the simulation process and its increase will enlarge the unit contact force between work roll and strip. The influence of deformation resistance on axial force cannot be clearly described. So the ratio of axial force to rolling force of each deformation resistance is calculated and shown in Figure 7(b). It can be seen that the ratio of axial force to rolling force first decreases when the deformation resistance is less than $600 \mathrm{MPa}$ and then remains relatively stable.

\section{Profile Configuration of Rolls}

4.1. CVC Curve Design. It can be obtained from the above analysis that the axial force of work roll consists of two parts which generates from rolling force and interroll force, respectively. The maximum axial force is concerned in the common monomial coefficient designation process of work roll curve [13], while the occurrence frequency which is a very important factor for roll service condition is not 


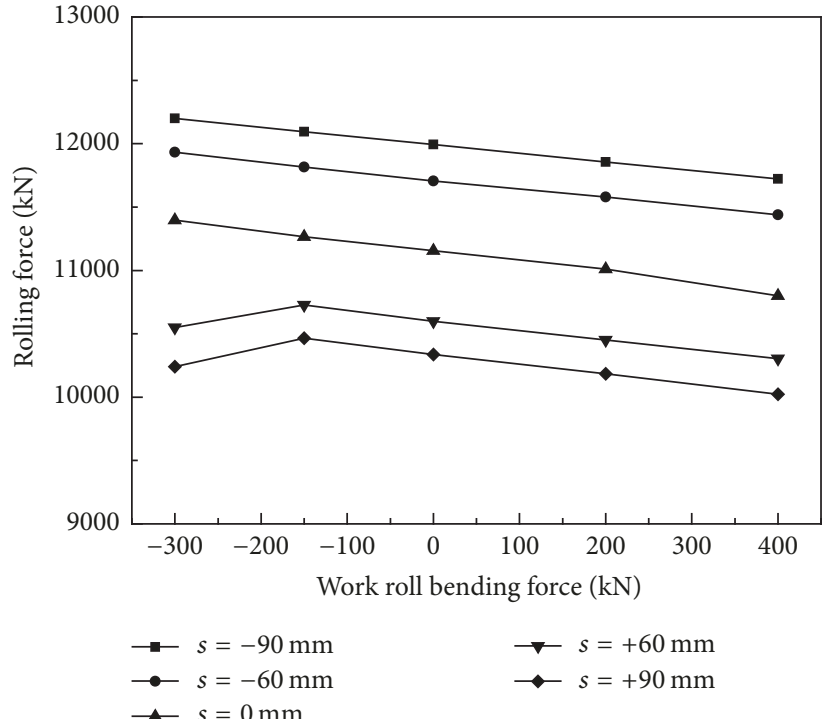

(a)

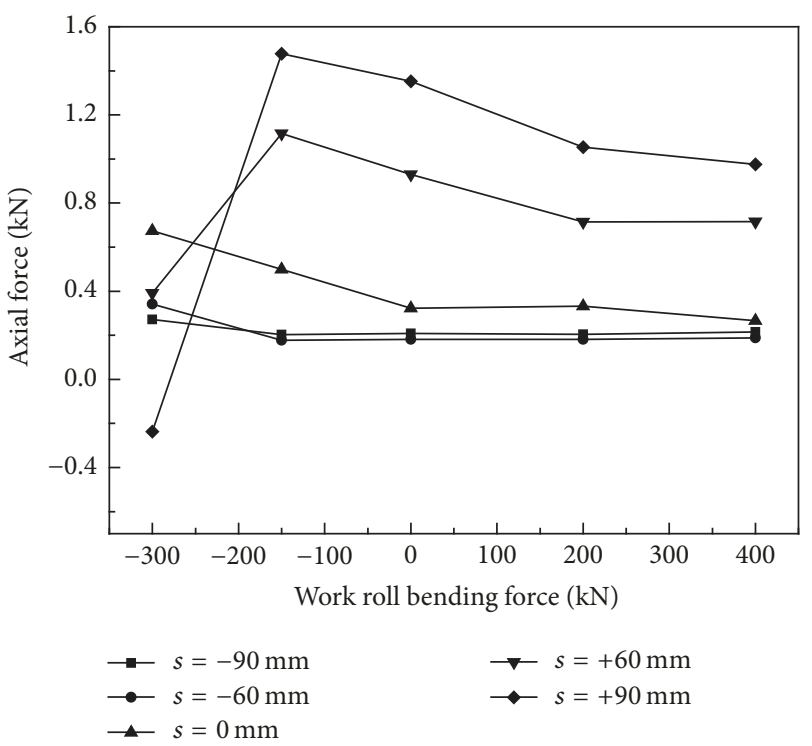

(b)

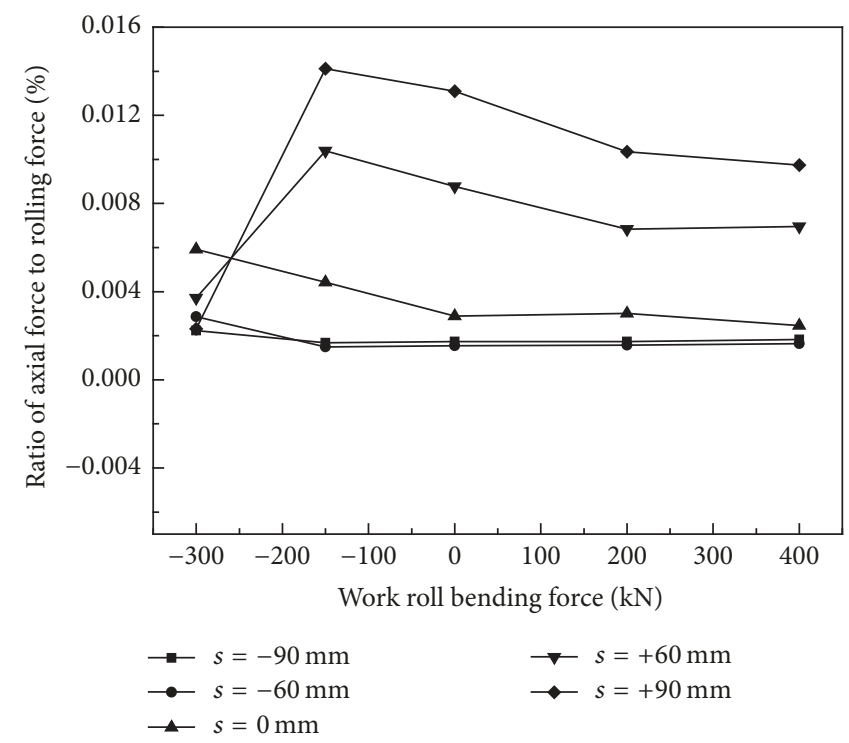

(c)

FIGURE 5: Influence on total axial force of work roll bending force. (a) Rolling force; (b) axial force; and (c) ratio of axial force to rolling force.

considered. That is to say the factors of product specification and classification are not considered. So it can be deduced that the monomial coefficient could not be the optimum one. The work roll shifting position and bending force are real time adjusting variables, while the rolling schedule is relatively stable in a certain period. Then a new axial force calculation method is adopted considering the main technical influence factors of strip width and deformation resistance. In the newly established method, the work conditions combined with strip width and deformation resistance are considered by weighting coefficient as expressed in

$$
\min \left(\sum_{i=1}^{n} \eta(i)\left|P_{x}(i)+Q_{x}(i)\right|\right),
$$

where $\eta(i)$ is the ratio of work condition $i$ among all common conditions; $P_{x}(i), Q_{x}(i)$ are the axial forces generated from rolling force and interroll contact force, respectively.

According to the former research, the quadratic coefficient $A_{2}$ and cubic coefficient $A_{3}$ are related to strip crown control range [15]. So coefficients $A_{2}$ and $A_{3}$ are determined by the same method. $A_{0}$ is the nominal radius of work roll $R_{0}$, which varies with work roll grinding. For the third-order CVC curve, there are two extreme points within the range of work roll length, so the range of $A_{1}$ could be determined as [29]

$$
\frac{A_{2}^{2}}{3 A_{3}}<A_{1}<\frac{A_{2}^{2}}{3 A_{3}}-\frac{3 A_{3}(2 L)^{2}}{4} \quad A_{3}<0
$$




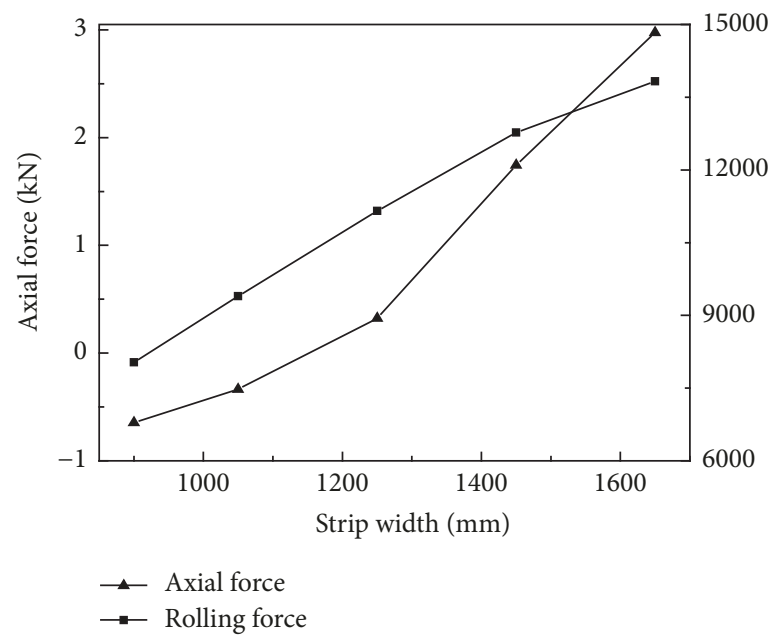

(a)

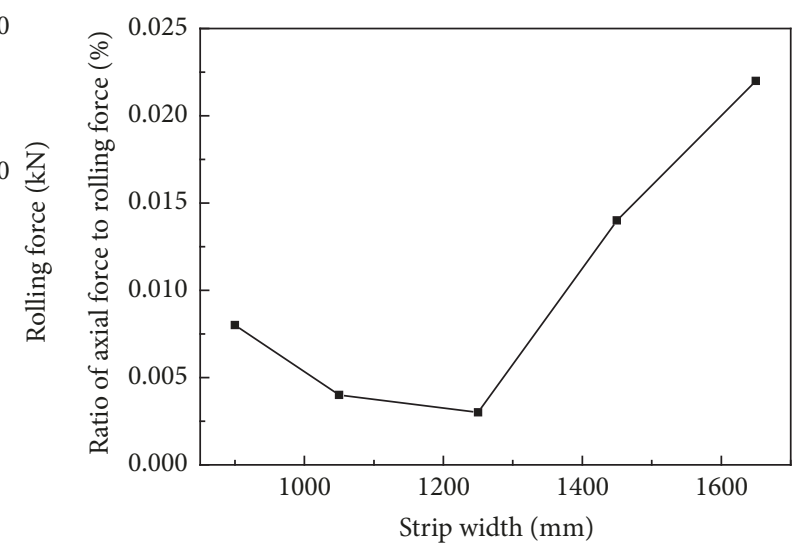

(b)

FIGURE 6: Influence of strip width on total axial force and rolling force. (a) Axial force and rolling force; (b) ratio of axial force to rolling force.

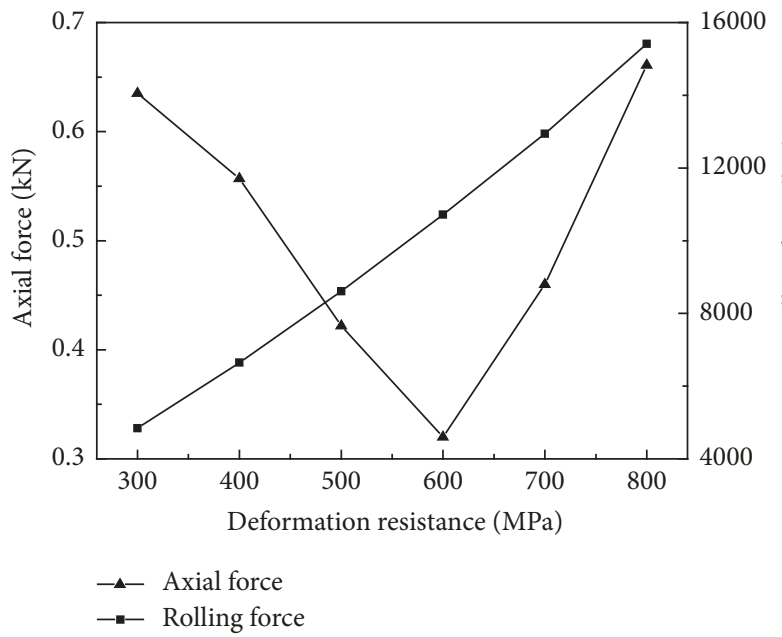

(a)

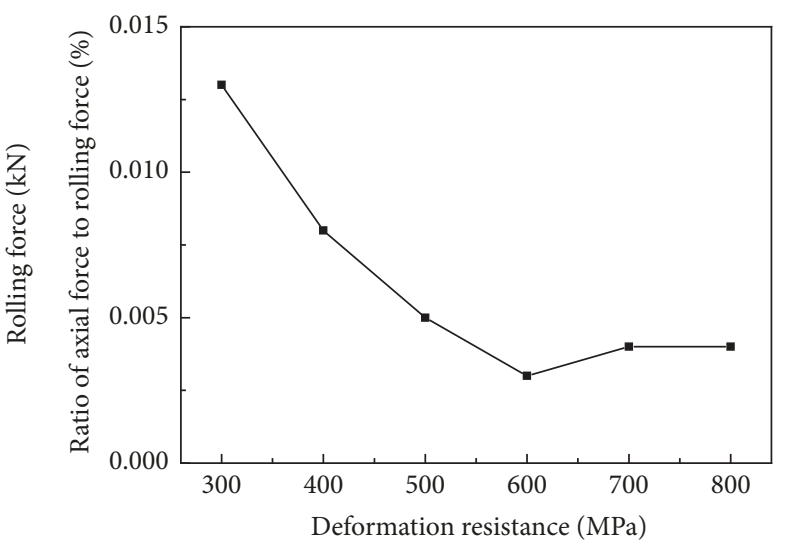

(b)

Figure 7: Influence of deformation resistance on total axial force and rolling force. (a) Axial force and rolling force; (b) ratio of axial force to rolling force.

$$
\frac{A_{2}^{2}}{3 A_{3}}-\frac{3 A_{3}(2 L)^{2}}{4}<A_{1}<\frac{A_{2}^{2}}{3 A_{3}} \quad A_{3}>0 .
$$

In order to keep the strip stable in the rolling process, the minimization of work roll diameter difference along the barrel is also considered. Firstly, the designed crown control range is corresponding to the maximum strip width rather than the roll gap edge. Secondly, the maximum roll diameter difference is between the two edges of work roll ends [30]. The calculation flowchart is shown in Figure 8.

Figure 9 shows the comparison of work roll contours of original used curve to curves with Lu's design method and the new established method. It can be seen that the maximum roll radius differences of the original used curve and curves of Lu's design method and new established method are $0.649 \mathrm{~mm}$,
$0.596 \mathrm{~mm}$, and $0.817 \mathrm{~mm}$. The profile of the newly designed curve is similar to the original used curve, and the maximum roll radius of them both locates at the roll's right end, while it locates in the middle around $631 \mathrm{~mm}$ to the roll's left end for the curve designed by Lu's method. The maximum crown regulation range of original used curve is $0 \sim 0.557 \mathrm{~mm}$ for the maximum rolling gap width, $1750 \mathrm{~mm}$, which cannot meet the requirement of crown control ability, $0 \sim 0.7 \mathrm{~mm}$. The maximum crown regulation range of curve designed by Lu's method and the newly established method both is 0 $0.7 \mathrm{~mm}$ for the maximum rolling gap width, $1750 \mathrm{~mm}$. So the values of coefficients $A_{2}$ and $A_{3}$ of these two methods are identical. The coefficients of original used curve, Lu's design method, and new established method are listed in Table 1. The values of coefficient $A_{1}$ of the two design methods are different as a result of the different axial force optimization 


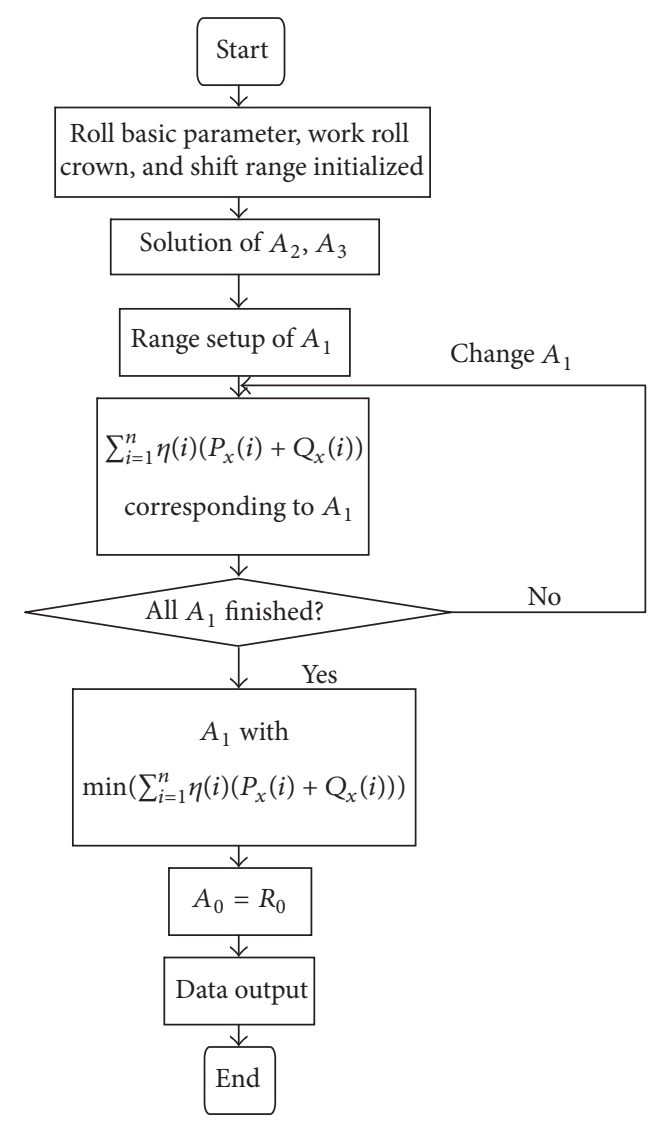

FIGURE 8: Flowchart of CVC roll curve designation.

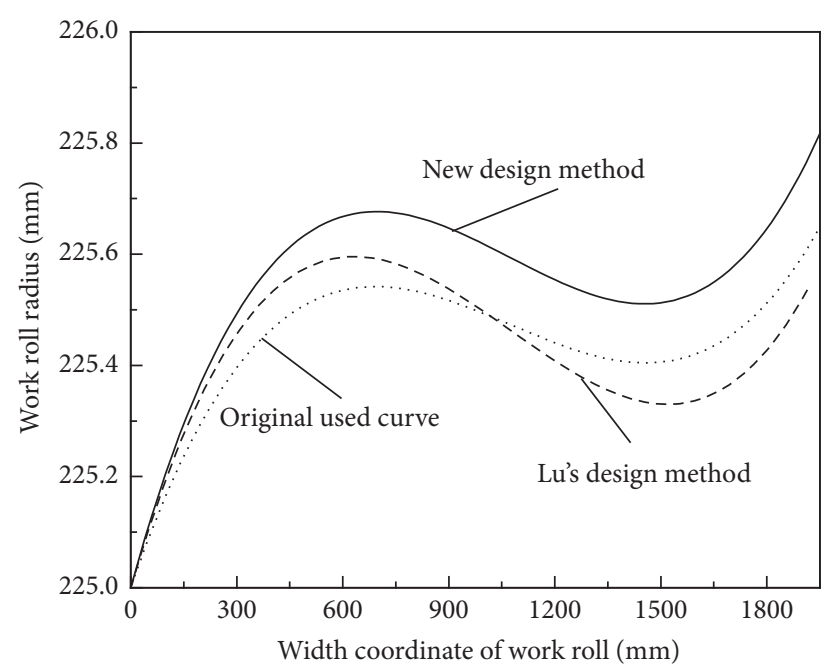

FIGURE 9: Comparison of work roll contour of different designing method.

algorithms which lead to the profile difference as shown in Figure 9.

Figure 10 shows the influence of strip width and deformation resistance on axial force with different CVC curves. It can be seen that the axial force increases with the increase of strip width and deformation resistance. It presents a different
TABle 1: Coefficients of third-order curve with different design methods.

\begin{tabular}{lccc}
\hline $\begin{array}{l}\text { Design } \\
\text { method }\end{array}$ & $A_{1}$ & $A_{2}$ & $A_{3}$ \\
\hline $\begin{array}{l}\text { Original used } \\
\text { curve }\end{array}$ & $1.8584 e-2$ & $-1.97896 e-6$ & $6.13631 e-10$ \\
$\begin{array}{l}\text { Lu's design } \\
\text { method }\end{array}$ & $2.1915 e-2$ & $-2.45714 e-6$ & $7.61905 e-10$ \\
$\begin{array}{l}\text { New } \\
\text { established } \\
\text { method }\end{array}$ & $2.3132 e-2$ & $-2.45714 e-6$ & $7.61905 e-10$ \\
\hline
\end{tabular}

variation regularity compared to the original used CVC curve as shown in Figures 6 and 7. The axial force is larger when the strip width is less than $1250 \mathrm{~mm}$ for Lu's design method, while it is larger when the strip width is larger than $1450 \mathrm{~mm}$ for the new design method as shown in Figures 10(a) and 10(c). This is because the strip width is considered as a major influence factor for the newly established curve design method. And in the corresponding production period, the product of 900 $1300 \mathrm{~mm}$ in width takes up nearly $75 \%$. The maximum axial force decreases from $5.23 \mathrm{kN}$ for Lu's design method to $1.5 \mathrm{kN}$ for the new design method in the above width range. This is very meaningful for extending the serve life of roller bearing. It can also be obtained that the axial force experiences smaller changes when strip width is between $900 \mathrm{~mm}$ and $1300 \mathrm{~mm}$, while it experiences greater changes when strip width is between $1300 \mathrm{~mm}$ and $1650 \mathrm{~mm}$ for the new designed CVC curve. But for Lu's design method, the axial force variation trend is just on the contrary. For Lu's design method, the change of axial force is little with the change of deformation resistance when strip width is $1450 \mathrm{~mm}$, while for the new design method the strip width changes to $1250 \mathrm{~mm}$. It can be seen from Figures 10(b) and 10(d) that the ratios of axial force to rolling force are relatively stable when strip width is larger than $1450 \mathrm{~mm}$ for Lu's design method, while it is relatively stable when strip width is less than $1300 \mathrm{~mm}$ for newly established method. This phenomenon demonstrates that the ability to resist axial force fluctuation of the new designed CVC curve is stronger for strip width between $900 \mathrm{~mm}$ and $1300 \mathrm{~mm}$. It proves that rolling schedule is really very critical for $\mathrm{CVC}$ work roll curve design and the monomial coefficient has a very significant effect on work roll axial force. It can be deduced that taking the work roll axial force minimization as the monomial coefficient design criteria of the third-order CVC curve is feasible and crucial.

4.2. Backup Roll Chamfer Design. There is a force concentration of the interroll contact force as shown in Figure 2(a). And the force concentration is harmful to the backup roll. The common approach to reduce the force concentration is machining a chamfer at the end of the backup roll. The length and depth of chamfer are the main factors influencing the force concentration. The style of chamfer may be linear, parabolic, sinusoidal, circular, or a compound type. In order to obtain a roll end chamfer with better comprehensive performance, the optimal design objective function considering the interroll force concentration, transverse stiffness of rolling 


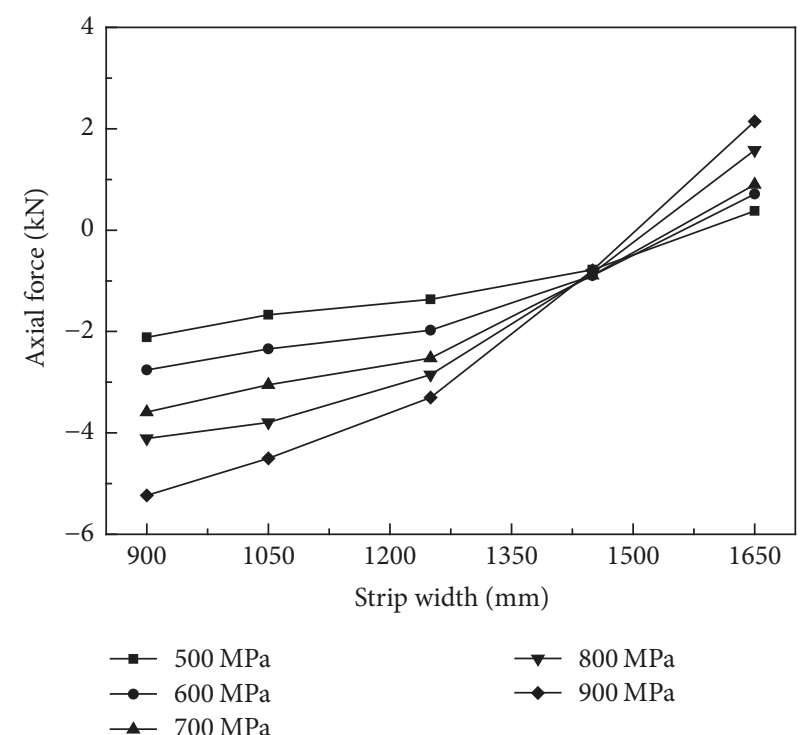

(a)

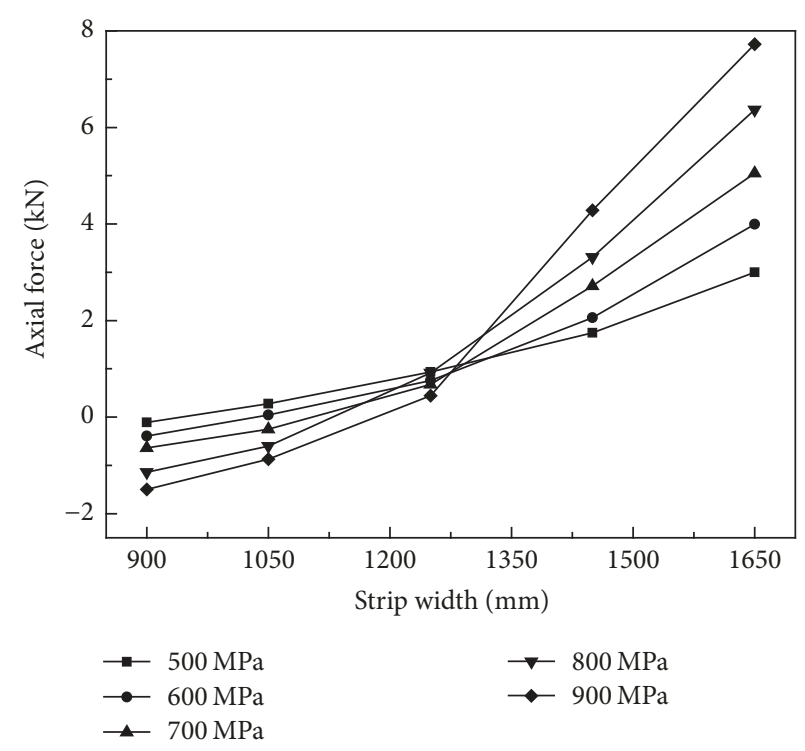

(c)

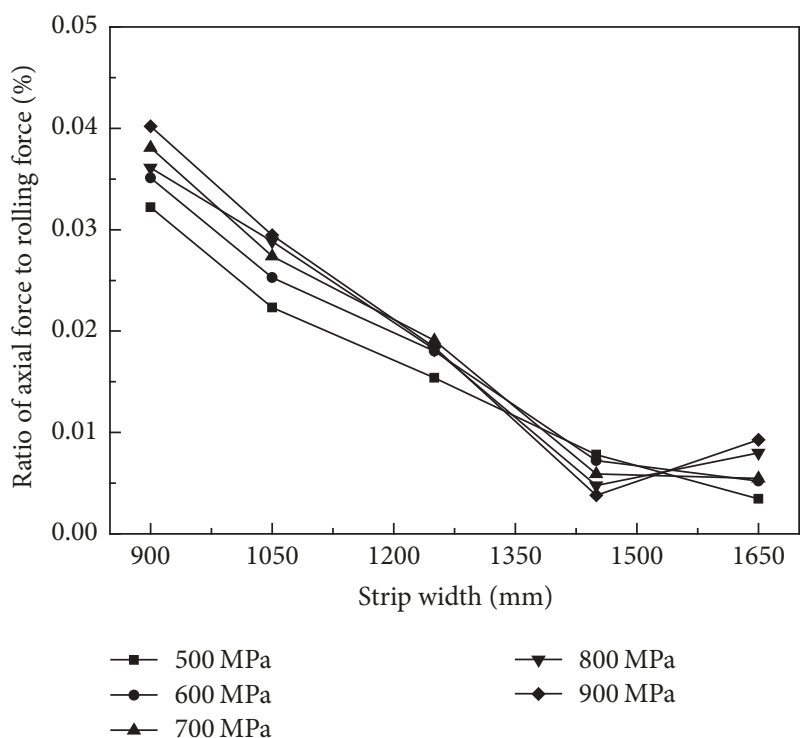

(b)

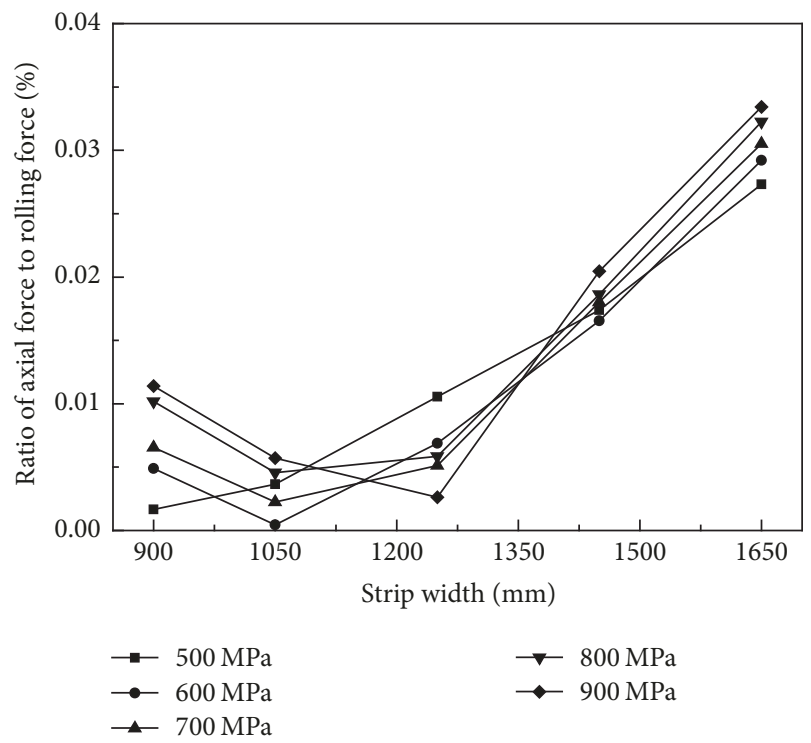

(d)

FIGURE 10: Influence of strip width and deformation resistance on work roll axial force. (a) Axial force of Lu's design method; (b) ratio of axial force to rolling force of Lu's design method; (c) axial force of new design method; and (d) ratio of axial force to rolling force of new design method.

force, and comprehensive work roll axial force is established as

$$
\begin{aligned}
& \min \left(\alpha_{q}\left(\sum_{i=1}^{n} v(i) \frac{q_{\max }(i)}{q_{\max 0}(i)}\right)+\alpha_{k}\left(\sum_{i=1}^{n} v(i) \frac{K_{P}(i)}{K_{P 0}(i)}\right)\right. \\
& \left.+\alpha_{x}\left(\sum_{i=1}^{n} v(i)\left|\frac{P_{x}(i)+Q_{x}(i)}{P_{x 0}(i)+Q_{x 0}(i)}\right|\right)\right),
\end{aligned}
$$

where $\alpha_{q}, \alpha_{k}$, and $\alpha_{x}$ are the weighting factor of interroll force concentration, transverse stiffness of rolling force, and work roll axial force; $\nu(i)$ is ratio of rolling condition $i$ among all rolling conditions; $q_{\max }(i)$ and $q_{\max 0}(i)$ are the maximum interroll force with and without backup roll chamfer; $K_{P}(i)$ and $K_{P 0}(i)$ are the transverse stiffness of rolling force with and without backup roll chamfer; $P_{x}(i)+Q_{x}(i)$ and $P_{x 0}(i)+Q_{x 0}(i)$ are the comprehensive work roll axial force with and without backup roll chamfer.

For this mill, the lengths of work roll and backup roll are $1950 \mathrm{~mm}$ and $1750 \mathrm{~mm}$, respectively. And the maximum work roll shifting distance is $100 \mathrm{~mm}$ to both driving side and operation side. So the ends of work roll barrel and backup roll barrel will be aligned at the maximum work roll shifting position. For the newly designed CVC curve, there are two extreme points which are $693 \mathrm{~mm}$ and $1460 \mathrm{~mm}$ to the barrel end of work roll operation side. So the length of backup roll chamfer should be less than $290 \mathrm{~mm}$, or it will cause a new interroll force concentration. The length and radius 


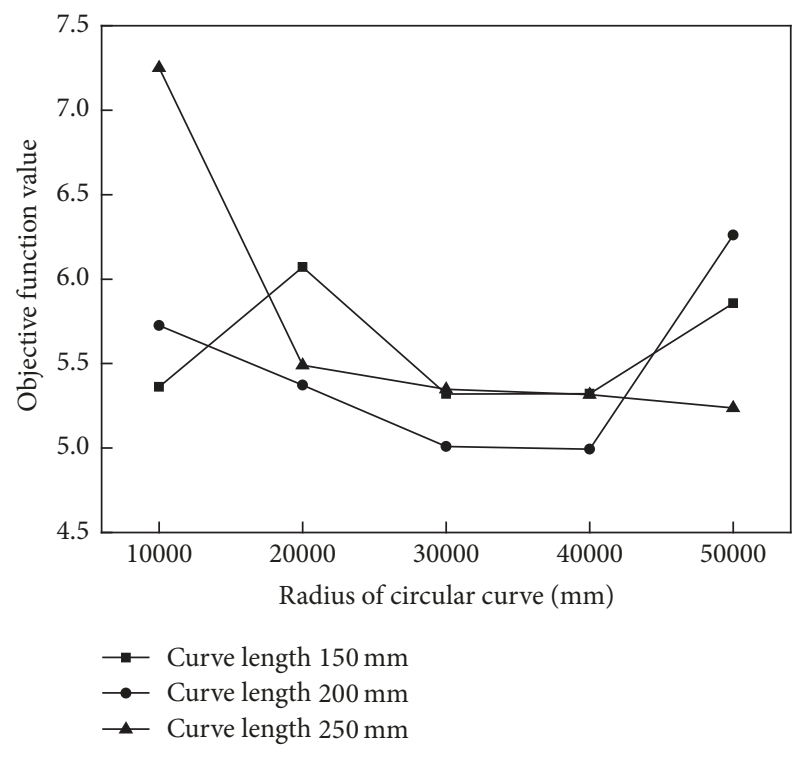

(a)

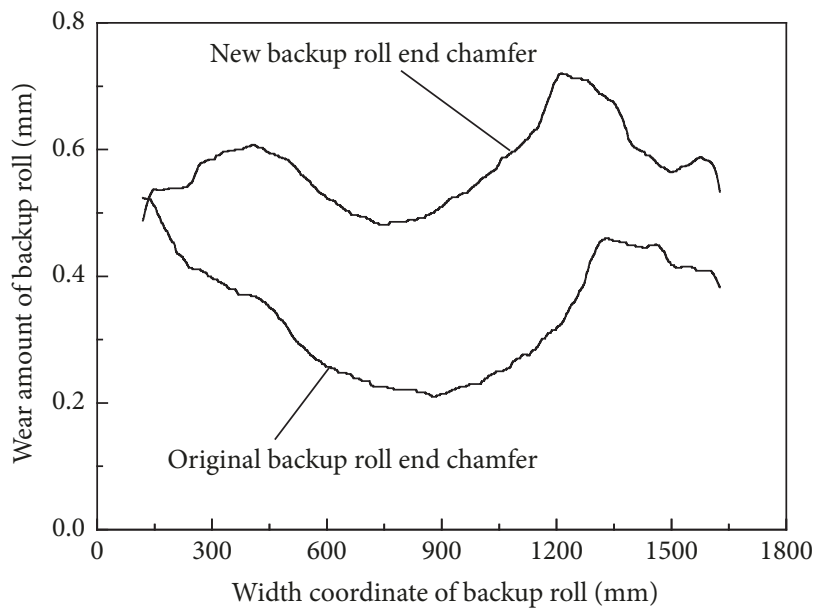

(b)

FIGURE 11: Objective function value and field application of optimized backup roll chamfer. (a) Objective function values; (b) wear of backup roll.

of original used circular chamfer are $150 \mathrm{~mm}$ and $9000 \mathrm{~mm}$, respectively, and the backup roll wear is still severe and uneven.

The circular chamfer is adopted in this backup roll chamfer optimal designing process. The curve length is set to $150 \sim$ $250 \mathrm{~mm}$ and the circular radius is set to $10000 \sim 50000 \mathrm{~mm}$. Considering strip width and deformation resistance as the main factors, the objective function values are obtained as shown in Figure 11(a). It can be seen that the objective function value is relatively small when the curve radius is between 30000 and $40000 \mathrm{~mm}$, especially with the curve length of $200 \mathrm{~mm}$. So the backup roll chamfer with curve length of $200 \mathrm{~mm}$ and circular radius $30000 \mathrm{~mm}$ is chosen for field application.

The wear of backup roll with original used chamfer curve and newly designed chamfer curve is measured with the roll grinder after a whole service cycle as shown in Figure 11(b). The distribution of backup roll wear is in an " $\mathrm{S}$ " shape which is similar to the interroll force. The lengths of rolled strip are different for the two backup rolls, so the maximum wear amount is not equal. The wear distribution is much more uneven for the original end chamfer especially for the roll end where there is an interroll force concentration. But the severe wear at the end of backup roll is alleviated obviously for the newly designed backup roll end chamfer. And the position with maximum wear quantity transfers from backup roll end to the extreme point with larger work roll radius as shown in Figure 9. The roll contour self-maintenance parameter and roll contour variation characteristic can be introduced to appraise the backup roll wear pattern [21-23]. For the original backup roll end chamfer, the self-maintenance parameter is $82.06 \%$. The roll contour variation characteristic can be evaluated as D which represents an inclined wear distribution along backup roll barrel. For the new backup roll end chamfer, the self-maintenance parameter is $86.32 \%$. The roll contour variation characteristic can be evaluated as $\mathrm{C}^{+}$which represents an asymmetric wear distribution with severe wear near the roll end. That is to say the newly established chamfer has a better service performance and the optimization algorithm is effective on reduction of interroll force concentration and homogenization of backup roll wear.

\section{Conclusion}

(1) A new comprehensive work roll axial force computing method for four-high CVC mill is proposed considering the comprehensive contact contour between work roll and backup roll or strip, respectively. The comprehensive work roll axial force is composited of the axial force applied by backup roll and strip.

(2) A new CVC work roll designing method is presented considering comprehensive work roll axial force minimization, work roll diameter difference minimization, and rolling schedule. The rolling schedule is very critical for CVC work roll curve design and the monomial coefficient has a very significant effect on comprehensive work roll axial force.

(3) Corresponding to the newly designed CVC curve, an optimal design model for backup roll end chamfer configuration is established considering the interroll force concentration, transverse stiffness of rolling force, and comprehensive work roll axial force. A systematical roll contour configuration scheme for four-high CVC mill is established.

\section{Conflicts of Interest}

The authors declare that there are no conflicts of interest regarding the publication of this paper. 


\section{Acknowledgments}

The authors would like to acknowledge the National Key Basic Research Program of China (no. 2012CB722801), National Natural Science Foundation of China (nos. 51404159 and 51504157), and Natural Science Foundation of Shanxi (nos. 2013021019-1 and 2015081011) for their financial support of the research.

\section{References}

[1] W. J. Edwards and P. D. Spooner, "Analysis of strip shape," Automation of Tandem Mills, A Collection of Monographs, Metals Society, pp. 176-212, 1973, London.

[2] K. N. Shohet and N. A. Townsend, "Roll bending methods of crown control in four high plate mill," Journal of the Iron and Steel Institute, vol. no.11, pp. 1088-1098, 1968.

[3] K. Nakajima, "Newly developed crown and shape control method in hot strip mill," in Proceedings of the International Conference on Steel Rolling, 1, pp. 544-555, Tokyo, Japan, 1980.

[4] Y. Tozawa and T. Ishikawa, "Study on stress distribution in strip rolling - rolling pressure and stresses at the upper stream side of roll gap," Memories of the Faculty of Engineering Nagoya University, vol. 36, no. 2, pp. 79-117, 1984.

[5] G. D. Wang, The Shape Control and Theory, Metallurgical Industry Press, Beijing, China, 1986.

[6] Z. Y. Jiang, D. Wei, and A. K. Tieu, "Analysis of cold rolling of ultra thin strip," Journal of Materials Processing Technology, vol. 209, no. 9, pp. 4584-4589, 2009.

[7] D. Y. Gong, J. Z. Xu, and F. C. Yuan, "Study on roll elastic deformation asymmetrical 4-high mill stiffness," Journal of Northeastern University (Natural Science), vol. 33, no. 11, pp. 1586-1590, 2012 (Chinese).

[8] X. G. Liang, "Preset model of bending force for six-high tandem cold rolling mill," Iron and Steel, vol. 49, no. 10, pp. 40-43, 2014 (Chinese).

[9] D. C. Wang, Y. L. Wu, and H. M. Liu, "High-efficiency calculation method for roll stack elastic deformation of four-high mill," Iron and Steel, vol. 50, no. 11, pp. 69-74, 2015 (Chinese).

[10] J. S. Chen, J. Wang, and W. Q. Han, "Study on models of work roll contact for tandem cold rolling process," Steel Rolling, vol. 33, no. 5, pp. 27-33, 2016 (Chinese).

[11] X. Yang, C. B. Hu, K.-X. Peng, and C.-N. Tong, "Load distribution of evolutionary algorithm for complex-process optimization based on differential evolutionary strategy in hot rolling process," Mathematical Problems in Engineering, vol. 2013, Article ID 675381, 8 pages, 2013.

[12] J. G. Cao, J. Zhang, and S. J. Zhang, Steel Rolling Equipments and Automation, Chemical Industry Press, Beijing, China, 1st edition, 2010.

[13] C. Lu, A. K. Tieu, and Z. Jiang, "A design of a third-order CVC roll profile," Journal of Materials Processing Technology, vol. 125126, pp. 645-648, 2002.

[14] G. C. Wei, J. G. Cao, J. Zhang, J. W. Hao, and G. Chen, "Optimization and application of CVC work roll contour on 2250 hot strip mills," Journal of Central South University (Science and Technology), vol. 38, no. 5, pp. 937-942, 2007 (Chinese).

[15] G. M. Liu, H. S. Di, and A. Chang, "Discussion on design of CVC roll contour and its equivalent crown," Journal of Northeastern University (Natural Science), vol. 29, no. 10, pp. 1443-1446, 2008 (Chinese).
[16] G. H. Yang, J. G. Cao, J. Zhang, S. Jia, and R. Tan, "Backup roll contour of a SmartCrown tandem cold rolling mill," Journal of University of Science and Technology Beijing: Mineral Metallurgy Materials, vol. 15, no. 3, pp. 357-361, 2008.

[17] Q. Wu, D. L. Sun, C. S. Liu, and C. G. Li, "Analysis of surface and sub-surface initiated spalling of forged cold work rolls," Engineering Failure Analysis, vol. 15, no. 4, pp. 401-410, 2008.

[18] A. D. Foster, J. Lin, D. C. J. Farrugia, and T. A. Dean, "A test for evaluating the effects of stress-states on damage evolution with specific application to the hot rolling of free-cutting steels," International Journal of Damage Mechanics, vol. 20, no. 1, pp. 113-129, 2011.

[19] D. Benasciutti, "On thermal stress and fatigue life evaluation in work rolls of hot rolling mill," Journal of Strain Analysis for Engineering Design, vol. 47, no. 5, pp. 297-312, 2012.

[20] N. Kong, J. Cao, Y. Wang et al., "Development of smart contact backup rolls in ultra-wide stainless strip rolling process," Materials and Manufacturing Processes, vol. 29, no. 2, pp. 129133, 2014

[21] J. Cao, X. Chen, Q. Xhang, and A. He, "Roll wear pattern and appraisal of roll contour in hot wide strip mill," Journal of University of Science and Technology Beijing, vol. 21, no. 2, pp. 188-190, 1999 (Chinese).

[22] J. G. Cao, S.-J. Liu, J. Zhang, P. Song, T.-L. Yan, and Y.-Z. Zhou, "ASR work roll shifting strategy for schedule-free rolling in hot wide strip mills," Journal of Materials Processing Technology, vol. 211, no. 11, pp. 1768-1775, 2011.

[23] G. Xu, X. J. Liu, W. J. Xiong, J. R. Zhao, and X. Q. Yu, “Appraisal of roll wear pattern of CVC mill," Iron and Steel Vanadium Titanium, vol. 27, no. 3, pp. 60-62, 2006 (Chinese).

[24] J. W. Hao, J.-G. Cao, J. Zhang, G.-C. Wei, Y.-Z. Zhou, and G. Chen, "Backup roll contour of 2250 CVC hot strip mill," Journal of Central South University (Science and Technology), vol. 38, no. 4, pp. 734-738, 2007 (Chinese).

[25] J. Q. Sun, H. X. Zhang, and X. R. Wang, "Optimization of backup roll chamfer shape for four high CVC rolling mill," Angang Technology, vol. 3, pp. 1-5, 2008 (Chinese).

[26] G. M. Liu, H. S. Di, and L. Hao, "An analyses on contact pressure between rolls of 4-High CVC cold rolling mill," China Metallurgy, vol. 20, no. 2, pp. 11-14, 2010 (Chinese).

[27] D. F. Guo, J. Shao, and A. R. He, "Research on working performance of backup roll chamfer for CVC tandem mill," Steel Rolling, vol. 27, no. 6, pp. 5-10, 2010 (Chinese).

[28] X. D. Wang, F. Li, and B. H. Li, "Development and application of pressure-equalizing back-up roll contour in hot strip mill," Iron and Steel, vol. 47, no. 7, pp. 44-48, 2012.

[29] W. He, The Curve Design of CVC Roll Profile And Research on Roll System Elastic Deformation, Master dissertation, Northeastern University, Shenyang, Liaoning, China, 2006.

[30] G. H. Yang, J.-G. Cao, J. Zhang, C. Wang, and S.-H. Jia, "Optimization of application of SmartCrown on tandem cold rolling mill," Iron and Steel, vol. 41, no. 9, pp. 56-59, 2006 (Chinese). 


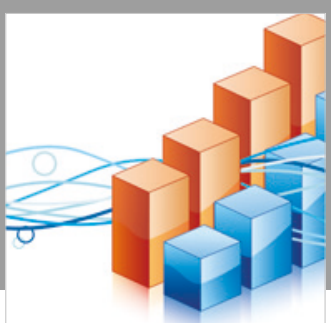

Advances in

Operations Research

\section{-n-m}
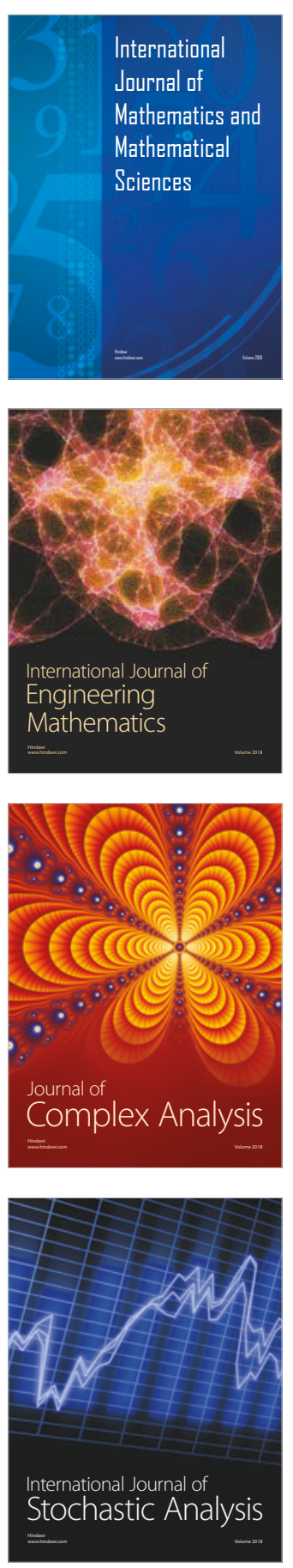
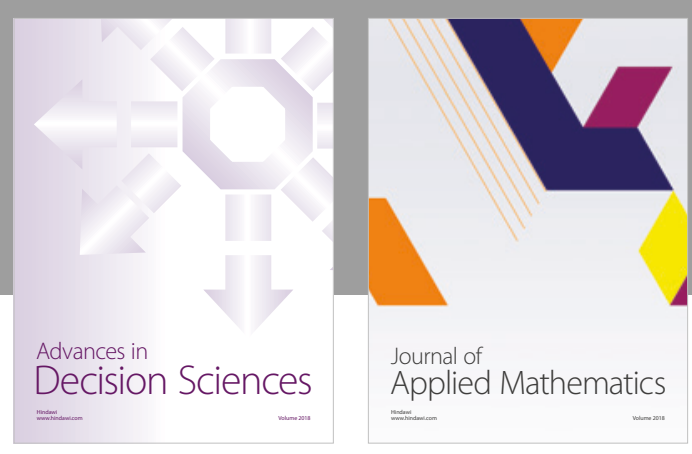

Journal of

Applied Mathematics
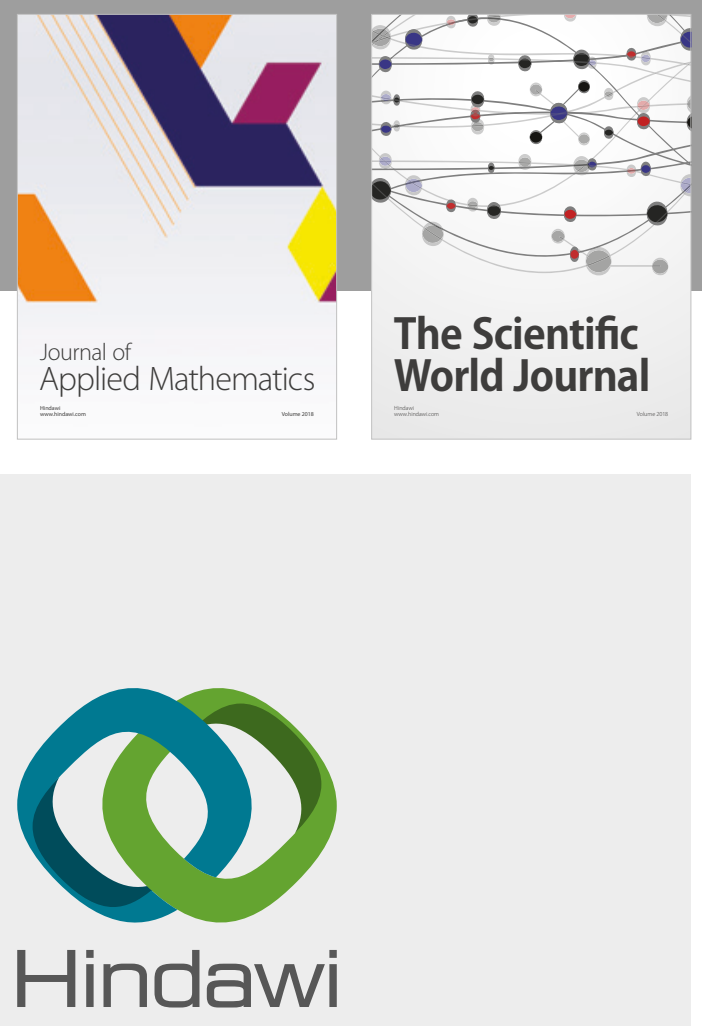

Submit your manuscripts at

www.hindawi.com

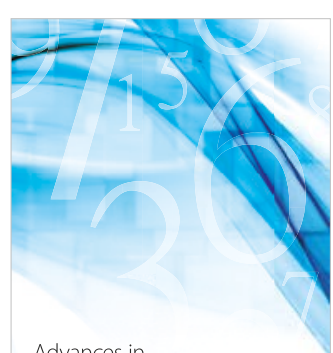

Advances in
Numerical Analysis
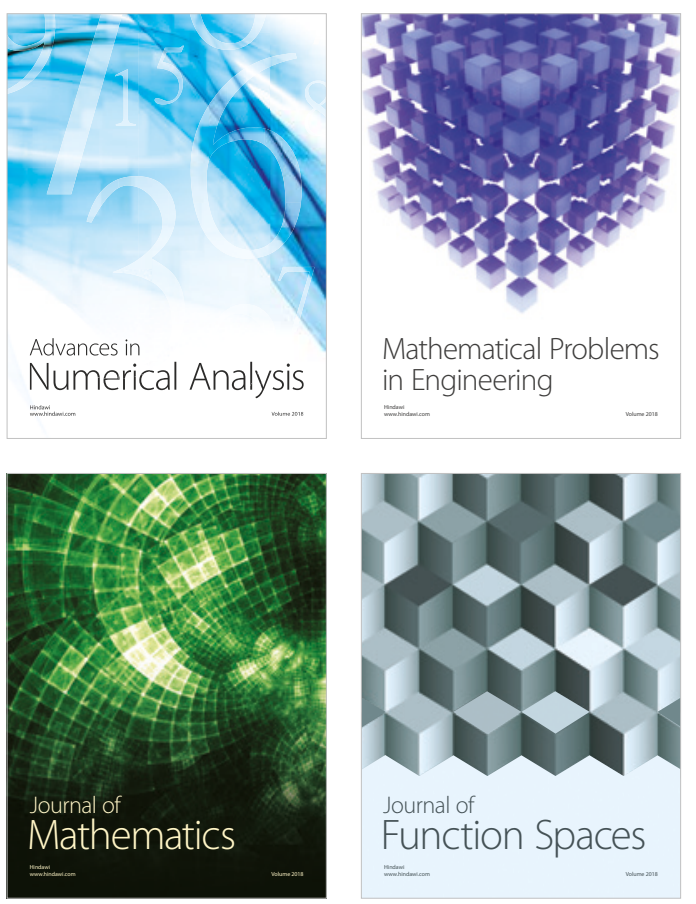

Mathematical Problems in Engineering

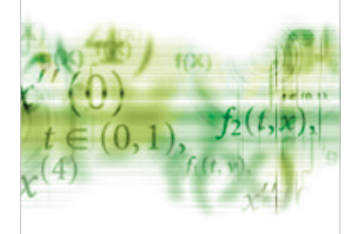

International Journal of

Differential Equations

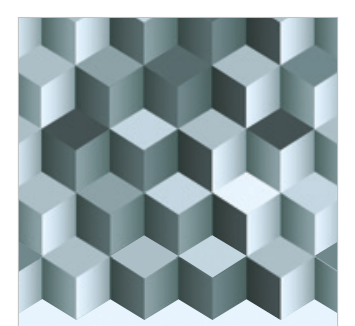

Journal of

Function Spaces

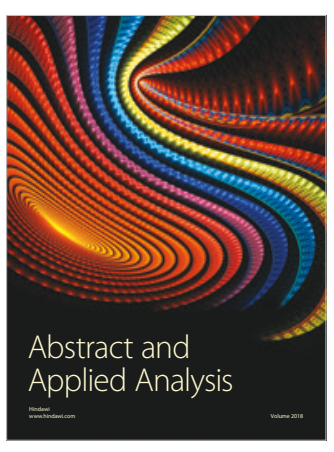

The Scientific

World Journal

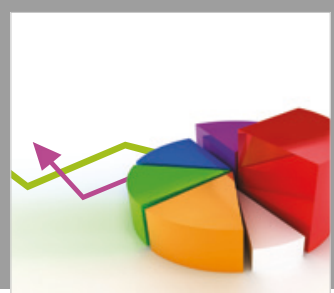

Journal of

Probability and Statistics
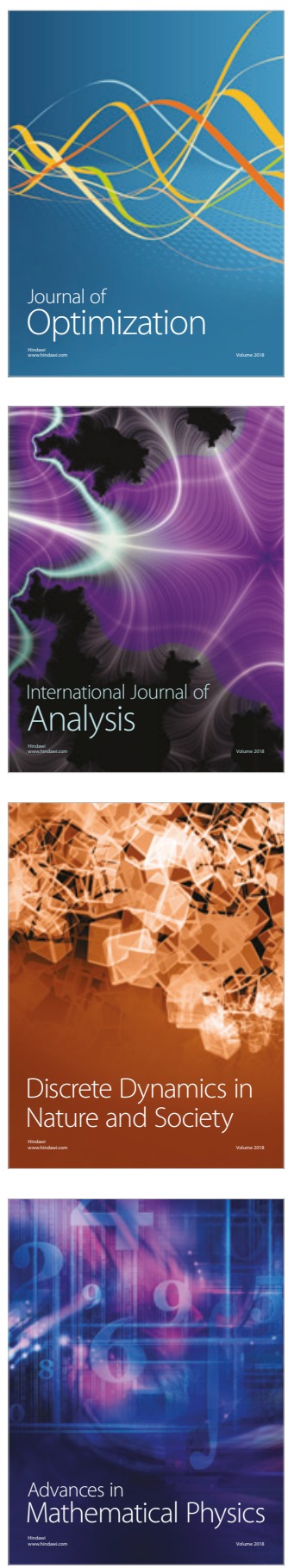